REVESCO. Revista de Estudios Cooperativos

ISSN: $1885-8031$

https://dx.doi.org/10.5209/REVE.69171

\title{
Las perspectivas Latinoamericana y Europea de la Economía Solidaria
}

\author{
Leomara Battisti Telles ${ }^{1}$, Carmen Marcuello Servós ${ }^{2}$ y Juliana Vitória Messias Bittencourt ${ }^{3}[$
}

Recibido: 29 de enero de 2018 / Aceptado: 7 de noviembre de 2019 / Publicado: 27 de mayo de 2020

Resumen. La Economía Solidaria se presenta como un modelo económico alternativo y ha sido un tema recurrente tanto en Latinoamérica y como en Europa. Sin embargo, no hay todavía una única definición aceptada con respecto a este modelo alternativo. En ocasiones se utilizan términos conceptualmente distintos, pero interconectados entre sí y, especialmente en relación a Economía Social. Así, el debate sobre la temática de los términos que definen las nuevas experiencias económicas, centradas en valores humanos y de solidaridad, que se oponen al modelo económico vigente, es muy relevante para el avance de esas nuevas formas de hacer economía. Así, el objetivo de este trabajo es analizar el contexto de la Economía Solidaria a partir de las vertientes latinoamericana y europea. Para ello, se analizan los principales autores acerca del tema, con el fin de examinar los conceptos, definiciones y el reconocimiento legal de la Economía Solidaria en ambos continentes. Asimismo, se estudian las principales plataformas de la Economía Social y Solidaria a nivel nacional, regional y/o mundial. De los resultados, se observa la evolución del concepto de la Economía Solidaria en Latinoamérica y en Europa. Más allá de sus diferentes evoluciones, en ambos continentes la Economía Solidaria se presenta como una economía alternativa al sistema capitalista vigente, que muestra que es posible aportar la solidaridad a las relaciones económicas. Sin embargo, queda pendiente todavía un mayor debate sobre la delimitación conceptual y organizativa de la Economía Solidaria. Asimismo, actualmente ocho países de Latinoamérica y once de Europa reconocen legalmente la Economía Solidaria por medio de leyes, decretos, secretarias y/o institutos lo que muestra los avances realizados.

Palabras clave: Economía Solidaria; Economía Social y Solidaria; Solidaridad; Conceptos; Reconocimiento legal; Plataformas.

Claves Econlit: A13; L30; L39.

\section{[en] The Latin American and European perspectives of Solidarity Economy}

Abstract: The Solidarity Economy is presented as an alternative economic model and has been a recurring theme both in Latin America and in Europe. However, there is not yet a single accepted definition with respect to this alternative model. Sometimes conceptually different terms are used, but interconnected with each other and, especially in relation to Social Economy. Thus, the debate on the subject of the terms that define new economic experiences, centred on human values and solidarity, which oppose the current economic model, is very relevant for the advancement of these new ways of doing economics. Thus, the objective of this work is to analyse the context of the Solidarity Economy from the Latin American and European aspects. For this, the main authors are analysed on the subject, in order to examine the concepts, definitions and legal recognition of the Solidarity Economy in both continents. Likewise, the main platforms of the Social and Solidarity Economy at national, regional and/or global level are studied. From the results, the evolution of the concept of the Solidarity Economy in Latin America and in Europe is observed. Beyond its different evolutions, in both continents, the Solidarity Economy presents itself as an alternative economy to the current capitalist system, which shows that it is possible to contribute solidarity to economic relations. However, a greater debate is still pending on the conceptual and organizational delimitation of the Solidarity Economy. Also, currently eight countries in Latin America and eleven in Europe legally recognize the Solidarity Economy through laws, decrees, secretaries and/or institutes which shows the progress made.

Keywords: Solidarity Economy; Social and Solidarity Economy; Solidarity; Concepts; Legal recognition; Platforms.

Sumario. 1. Introducción. 2. La economía solidaria en Latinoamérica. 3. La economía solidaria en Europa. 4. Las plataformas de la economía solidaria. 5. Consideraciones finales. 6. Referencias bibliográficas.

Cómo citar. Battisti Telles, L.; Marcuello Servós, C.; Messias Bittencourt J.V. (2020) Las perspectivas Latinoamericana y Europea de la Economía Solidaria. REVESCO. Revista de Estudios Cooperativos, vol. 134, e69171. https://dx.doi.org/10.5209/reve.69171.

1 Universidade Tecnológica Federal do Paraná (UTFPR), Instituto Federal do Paraná (IFPR), Brasil.

Dirección de correo electrónico: leomara.battisti@ifpr.edu.br.

2 Universidad de Zaragoza, España.

Dirección de correo electrónico: cmarcue@unizar.es.

3 Universidade Tecnológica Federal do Paraná (UTFPR), Brasil.

Dirección de correo electrónico: julianavitoria@utfpr.edu.br. 


\section{Introducción}

En general cuando se utiliza el término economía, se tiene la percepción de que no está incluida la faceta social de la misma. Esto es, se considera la cuestión social como un tema ajeno a la economía, pero, en realidad la faceta social no puede ser separada de la cuestión económica, así como tampoco las cuestiones políticas y culturales (Coraggio, 2004). Sin embargo, existen diferentes enfoques alternativos sobre la economía, que se oponen al modelo capitalista vigente y que consideran las relaciones económicas interconectadas con las relaciones políticas, culturales y sociales. En estos enfoques están comprendidas las organizaciones que tienen como objetivo principal las personas y la solidaridad en todas las fases del ciclo económico.

Sin embargo, las definiciones de los conceptos en torno a estas organizaciones que tienen como base la solidaridad, la autogestión y la lucha contra la pobreza y las desigualdades sociales, no presentan una propuesta generalmente aceptada con respecto a la diferenciación de los diversos términos utilizados: Tercer Sector, Economía Social, Economía Solidaria, Economía Social y Solidaria, Economía Popular, Economía Informal, Economía del Bien Común, entre otros. Para França Filho (2002), a pesar de no haber claridad en cuanto a las diferencias y las fronteras conceptuales, la respuesta a lo que tienen en común es más clara, sugiriendo que esas organizaciones, independientemente de la terminología usada para clasificarlas, tienen en común el hecho de ocupar un espacio de vida social y de trabajo que está entre las esferas del Estado y del mercado.

La presencia de diversos términos conceptualmente distintos, pero interconectados entre sí, provocan la falta de definiciones generalmente aceptadas y en algunos casos se utilizan como sinónimos. Sin embargo, cada concepto representa un contexto específico y las diferencias entre los mismos, en la concepción de França Filho (2002, p. 17) "están relacionadas con el propio contexto o lugar socio-histórico donde se elaboraron".

Estudios anteriores han abordado los factores que se aproximan y los factores que diferencian estos términos. Entre ellos destacan los trabajos de França Filho (2002) trata de establecer una frontera con respecto a los significados de los mismos; Laville (2004) demuestra que el debate sobre los diferentes significados de la economía merece ser reabierto y mantenido; Da Ross (2007) presenta las dos principales vertientes de la Economía Solidaria (la europea y la latinoamericana) y sus fundamentos teóricos; Guerra (2007) muestra un diálogo de diversos autores sobre cómo denominar el conjunto de experiencias y movimientos que han surgido en los últimos años en los distintos países, inspirado en valores solidarios y articulados en torno al modelo asociativo; Gaiger (2009) trata de las nuevas formas de organización y movilización colectivas asociadas al concepto de Economía Solidaria, comparando realidades y denominaciones que demarcan antecedentes históricos de la Economía Solidaria o gravitan en torno a las prácticas actuales de solidaridad, como la Economía Social y el Tercer Sector; y, Pérez de Pérez de Mendiguren e Etxezarreta (2015) reflexionan sobre el paisaje teórico y empírico al que nos aboca el uso cada vez más extendido del concepto hibrido de Economía Social y Solidaria. Entre los términos más debatidos en estos estudios están la Economía Solidaria y la Economía Social, que en algunos casos suelen ser utilizados juntos (Economía Social y Solidaria) en forma de complementariedad entre los dos conceptos.

Tanto la Economía Social (Monzón y Chaves, 2012) como la Economía Solidaria (Singer, 2002) aparecen históricamente vinculadas a las primeras cooperativas a finales del siglo XVIII principios del siglo XIX, en respuesta a los problemas sociales resultantes de la Revolución Industrial, iniciada en Inglaterra, no influenciadas directamente por ninguna corriente de pensamiento. El movimiento cooperativismo inglés fue influenciado por Robert Owen principalmente a través de la creación de la Cooperativa de Rochdale, en 1844, por 28 trabajadores, de los cuales seis eran seguidores de los pensamientos de Owen (Monzón y Chaves, 2012).

Mónzon y Chaves (2012) afirman que los principios cooperativos que regían el funcionamiento de la experiencia de Rochdale contribuyeron notablemente al concepto moderno de Economía Social. Y Singer (2002) menciona que Owen también contribuyó significativamente a la Economía Solidaria, por ser uno de los primeros pensadores a defender propuestas alternativas, de carácter autogestionario, para combatir la pobreza de los trabajadores provocada por la difusión de las máquinas y de la organización fabril de la producción.

La dificultad de lograr un consenso en la conceptualización de la Economía Solidaria se debe a la complejidad que comprende la propuesta de un modelo económico alternativo y también debido al desarrollo distinto de su concepto en dos importantes vertientes teóricas apuntadas por França Filho (2002) y Da Ross (2007): La vertiente latinoamericana y la vertiente europea.

De Ross (2007) menciona que la expresión Economía Solidaria fue forjada en Latinoamérica a principios de los años 1980, teniendo como principal representante el sociólogo chileno Luis Razeto. Sus pensamientos tuvieron especial aceptación de la iglesia católica en todo el continente, especialmente en Cáritas. Además, otras entidades como universidades y organizaciones de trabajadores, en diversos países contribuyeron al desarrollo del concepto y de experiencias de Economía Solidaria. En Europa, el surgimiento de la expresión 
Economía Solidaria se remonta a finales de los años 1980, a partir de la fuerte cultura de cooperativismo y economía social. Se desarrolló en un nivel teórico-académico y otro práctico, en el campo de la Economía de Inserción y de servicios de proximidad (Da Ross, 2007).

Sin embargo, no es nuestro propósito discutir los conceptos de cada uno de estos términos o sus prácticas, sino debatir el contexto de la Economía Solidaria. Por lo tanto, este artículo tiene como objetivo amañozar el contexto de la Economía Solidaria a partir de las vertientes latinoamericana y europea, con el fin de contribuir al avance del debate sobre los distintos enfoques.

Para ello, el artículo además de la Introducción se organiza con la siguiente estructura: en el siguiente apartado se presenta la Economía Solidaria en Latinoamérica, aportando los conceptos de los principales teóricos latinoamericanos y el reconocimiento legal de la misma en este continente; en el apartado tercero se describe la Solidaria en Europa, aportando los conceptos de los principales teóricos europeos y el reconocimiento legal de la misma en este continente; en el apartado cuarto, se examinan las Plataformas de la Economía Solidaria, que tienen con finalidad la promoción de la Economía Solidaria en el mundo; y, en el último apartado se destacan las principales conclusiones.

\section{La Economía solidaria en Latinoamérica}

\subsection{Conceptos}

Según Da Ross (2007) se puede afirmar que la denominación Economía Solidaria nace en Latinoamérica y actualmente está formado por movimientos y experiencias en todos los países del continente. Para Guerra (2004, p. 5) en Latinoamérica la Economía Solidaria asume "características más radicales de las que se encuentran en otros contextos y un discurso marcadamente más político", desempeñando un papel relevante en la lucha de los problemas sociales endógenos del sistema económico vigente. Entre los diversos teóricos e investigadores del tema en Latinoamérica destacan Luis Razeto (Chile), Paul Singer (Brasil), José Luis Coraggio (Argentina) y Pablo Guerra (Uruguay).

Razeto (1999) señala que la Economía Solidaria implica producir, distribuir, consumir, acumular y desarrollar con solidaridad, donde la solidaridad se introduzca en la economía misma, operando y actuando en las diversas fases del ciclo económico, provocando una transformación estructural en la economía, generando nuevos y verdaderos equilibrios. Este autor (Razeto, 2010) caracteriza la Economía Solidaria como una forma alternativa de hacer economía, basada en la solidaridad y el trabajo, generando beneficios sociales y culturales que benefician a la sociedad, a través de experiencias práctica y de teorías científicas. Postula un desarrollo alternativo, que sea integral, incluyendo el desarrollo humano, sostenible y con énfasis local.

Razeto (2002) también menciona que la Economía Solidaria se constituye como una propuesta eficaz y un proyecto integrador de los esfuerzos necesarios para producir desarrollo social y superar la pobreza, especialmente eficaz en contextos económicos caracterizados por altos niveles de desocupación y por acentuada desigualdad socioeconómica. En sus trabajos Luis Razeto utiliza especialmente la denominación economía de la solidaridad.

Singer (2005) presenta la Economía Solidaria como una experiencia liberadora que niega la separación entre el trabajo y el capital. Este autor (Singer, 2008) define la Economía Solidaria como un modo de producción que tiene como fundamentos primordiales la solidaridad, la división igualitaria de las ganancias y la autogestión, es decir, se caracteriza por la igualdad de derechos, donde los medios de producción son de posesión colectiva de los que trabajan con ellos y son gestionados por los propios trabajadores colectivamente de forma completamente democrática (autogestión). De acuerdo con Singer (2001) estas "empresas" incluyen diversas formas de organización asociativa voluntaria con el fin de proporcionar beneficios económicos a los asociados, como medio de enfrentamiento a los problemas sociales del modelo económico actual, principalmente la pobreza derivada de la falta de oportunidad de participar en el proceso de producción social. Así que recupera la dignidad humana, el auto-respeto y la ciudadanía de hombres y mujeres involucrados en ella.

Coraggio aborda en sus trabajos la economía de la solidaridad como la Otra Economía, una economía alternativa al modo capitalista. El utiliza diversos términos como "Economía Popular", "Economía Social", "Economía Social y Solidaria" y la que más defiende "Economía del Trabajo", que es una economía que produce sociedad y no sólo utilidades económicas, buscando satisfacer las necesidades de los mismos productores o de sus comunidades (necesidades de base territorial, étnica, social o cultural, además de la económica) y no está orientada por la acumulación de capital sin límites. Además, tiene como fundamento relaciones sostenibles de producción y reproducción y el trabajo y el conocimiento encarnado en los trabajadores y sus sistemas de organización (Coraggio, 2002). Coraggio $(2011 ; 2015)$ complementa que esa Otra Economía comprende una forma alternativa de economía que se opone al modelo hegemónico actual, a través de trabajo, de democratización, de libertad, de igualdad, de vida digna y de política. 
Guerra se centra más en la expresión Economía de la Solidaridad y señala que con esta hace referencia a "experiencias y comportamientos económicos que por sus lógicas, racionalidades, e instrumentos concretos de gestión, se distinguen tanto de la economía privada capitalista, como de la economía estatal" (Guerra, 2006, p. 28). Define la Economía Solidaria como un modelo alternativo al capitalismo, que comprende un conjunto de iniciativas populares y/o comunitarias de hacer economía en todas sus expresiones (producción, consumo, distribución, ahorro), fuertemente asociada al cambio social. Este fenómeno socioeconómico comprende tres dimensiones distintas: el movimiento social; el paradigma científico; y, el sector específico de nuestras economías de donde convergen las distintas experiencias de base solidaria (Guerra, 2010).

Aunque las conceptualizaciones y definiciones adoptadas por cada uno de los autores mencionados presentan diferencias, queda claro un consenso de que la caracterización de la Economía Solidaria se produce por medio de los valores del trabajo, de la igualdad de derechos, de la democracia, de la libertad, de la dignidad humana y de la justicia social. Esto es, se presenta como alternativa de transformación social y de enfrentamiento a los problemas endógenos del capitalismo.

\subsection{Organización y reconocimiento legal}

En Latinoamérica, uno de los primeros registros de lo que es hoy la Economía Solidaria ha sido en Colombia. En 1986 se adoptó el concepto de Economía Solidaria con el decreto 2536 del 4 de agosto que dio vida al Consejo Nacional de Economía Solidaria y lo reconoce como un sector de gran importancia en el entorno económico nacional. Y en 1988 con la ley 79 se organizan las formas solidarias del cooperativismo, asociaciones mutuales y fondos de empleados. Las entidades de Economía Solidaria estaban bajo la supervisión del Departamento Nacional de Cooperativas (Dancoop) hasta 1999. A partir de la Ley 454 de 1998, que transformó al Departamento Nacional de Cooperativas (Dancoop) en el Departamento Administrativo de la Economía Solidaria (Dansocial); y creó a la Superintendencia de la Economía Solidaria (Supersolidaria) y al Fondo de Garantías del Sector Cooperativo (Fogacoop), se tuvo el reconocimiento legal de la Economía Solidaria en Colombia (Colombia, 2018).

Todavía, el primer país en poseer una Ley relacionada con el tema fue Honduras, que aprobó por el Decreto 193/1985 la Ley del Sector Social de la Economía, que declara de interés público la organización, fomento y desarrollo del Sector Social de la Economía, para contribuir a humanizar el desarrollo económico y social del país.

La tabla 1 presenta los países en que se identificó el reconocimiento de la Economía Solidaria y/o la Economía Social en su legislación, sea en la constitución, o por medio de decreto y/o leyes nacionales o regionales, o aún creación de instituciones públicas oficiales de apoyo al desarrollo de esa otra economía. Se percibe el uso de términos distintos en cada país por lo que tratamos como reconocimiento legal de la Economía Social y Solidaria.

Tabla. 1. Reconocimiento legal de la Economía Social y Solidaria en Latinoamérica

\begin{tabular}{|c|c|}
\hline País & Ley \\
\hline Argentina & $\begin{array}{l}\text { Provincia de Buenos Aires (2014), Provincia de Entre Rios (2012), Provincia de } \\
\text { Mendoza (2012). Instituto Nacional de Economía Social (INAES). }\end{array}$ \\
\hline Bolivia & Contitución (2007) plantea la idea de Economía Plural. \\
\hline Brasil & $\begin{array}{l}\text { Proyecto de Ley 4865/2012. Subsecretaria Nacional de Economía Solidaria } \\
(2016)^{*} \text {. Leyes Municipales e Estadules ( } 18 \text { estados). }\end{array}$ \\
\hline Colombia & Ley 454/1998, de la Economía Solidaria \\
\hline Ecuador & $\begin{array}{l}\text { Constitución de la Republica } \\
\text { Ley Orgánica de la Economía Popular y Solidaria (2011) }\end{array}$ \\
\hline Honduras & Decreto 193/1985, Ley del Sector Social de la Economía \\
\hline Mejico & $\begin{array}{l}\text { Constituición de los Estados Unidos Mejicanos } \\
\text { Ley de la Economía Social y Solidaria (2012) }\end{array}$ \\
\hline Venezuela & $\begin{array}{l}\text { Constituición de la República Bolivariana de Venezuela (2008), articulo } 184 . \\
\text { Decreto 6130/2008, Ley para el fomento y desarrollo de la Economía Popular }\end{array}$ \\
\hline
\end{tabular}

Fuente: Elaboración propia.

* En 2016 la Secretaría Nacional de Economía Solidaria (SENAES) creada en 2003 dejó de ser Secretaria y pasó a ser Subsecretaria de Economía Solidaria, retroceso proveniente de las alteraciones promovidas en la estructura organizacional del Ministerio de Trabajo y Empleo por el Decreto 8894/2016. 
Para Gaiger (2009), en Latinoamérica, la Economía Solidaria se refiere esencialmente al conjunto de iniciativas que, a partir de la asociación libre y democrática de los trabajadores, buscando de beneficios económicos y de calidad de vida, reconocimiento y participación ciudadana. Las principales formas jurídicas de organización de los emprendimientos solidarios en Latinoamérica son cooperativas y asociaciones, pero hay también grupos informales, sociedades mercantiles y otras formas de organización que siguen los principios de solidaridad, democracia y autogestión, con foco en la vida humana y en la dignidad del trabajador.

França Filho (2002, p. 14) comenta que "en la práctica, el término Economía Solidaria identifica hoy una serie de experiencias organizacionales inscritas en una dinámica actual en torno a las llamadas nuevas formas de solidaridad". Estas experiencias también conocidas como emprendimientos de Economía Solidaria se caracterizan, según Gaiger (2013), por el desarrollo de actividad de producción, prestación de servicios, comercialización, finanzas y consumo con carácter solidario.

Se destaca que la legislación y la reglamentación de esos emprendimientos son definidas individualmente por cada país. Sin embargo, no es la forma jurídica que define una organización como solidaria o no, lo que las definen son los valores y principios que orientan sus prácticas. Como ejemplo, la Ley 454/1998, de Colombia define en el artículo $2^{\circ}$, "denominase Economía Solidaria al sistema socioeconómico, cultural y ambiental conformado por el conjunto de fuerzas sociales organizadas en formas asociativas identificadas por prácticas autogestionarias solidarias, democráticas y humanistas, sin ánimo de lucro para el desarrollo integral del ser humano como sujeto, actor y fin de la economía”.

\section{La Economía Solidaria en Europa}

\subsection{Conceptos}

En Europa se puede observar que hay un mayor reconocimiento e investigaciones en el campo de la Economía Social, donde la Economía Solidaria es considerada un subsector, parte de su tronco común (Monzón y Chaves, 2008). Sin embargo, se ha utilizado de forma frecuente el término hibrido Economía Social y Solidaria para abarcar las organizaciones de transformación social y de carácter solidario. Entre los más diversos teóricos e investigadores de la Economía Solidaria en Europa, se destaca Jean-Louis Laville (Francia).

Laville, sociólogo francés, es uno de los pioneros y principal teórico europeo de Economía Solidaria, y tiene como referencia la obra de Karl Polanyi, especialmente el concepto de economía plural, que aporta formas de regulación y producción social más allá del mercado (que es excluyente y generador de miseria). También aporta otras formas de economía, que incluyen los conceptos de domesticidad (producir para su propio usufructo), de reciprocidad (relaciones establecidas entre varias personas, donde las transferencias son indisociables de las relaciones humanas) y de redistribución (la producción queda a cargo de una autoridad que tiene la responsabilidad de distribuirlas) (França Filho y Laville, 2004).

Laville (2001, p. 85) define la Economía Solidaria como "el conjunto de las diversas actividades económicas (mercantil, no mercantil y no monetaria) que contribuyen a la democratización de la economía a partir del compromiso de los ciudadanos". Laville (2009) también menciona que la Economía Solidaria tiene su origen en los movimientos populares y que reconoce el saber popular, caracterizándola como un modo de vida y una manera diferente de hacer política, que combate la exclusión por medio de organización social, política y cultural que ofrece acceso a derechos. Además, el autor plantea la doble dimensión de la Economía Solidaria: (socio) política y (socio) económica.

Por lo tanto, la Economía Solidaria reconoce el carácter plural de los principios económicos y se presenta como una economía alternativa al sistema económico vigente, por medio de diferentes iniciativas de cuño popular (Laville, 2010). Además, presenta diferentes lógicas alternativas en un contexto de quiebra de los mecanismos de regulación económico-políticos de la sociedad actual (el estado y el mercado) y trae "nuevas" interacciones que no tienen relación con la lucha de clases, sino en cuestiones de lucha por el lugar de los individuos en la sociedad (França Filho y Laville, 2004).

La Figura 1 presenta el conjunto de actividades que componen la Economía Solidaria de acuerdo con Laville, donde las actividades de la Economía Solidaria buscan equilibrar la combinación entre diferentes recursos: mercantiles, obtenidos por el resultado de ventas; no mercantiles, provenientes de la redistribución; y no monetarios, provenientes de la contribución voluntaria. 
Figura. 1. La Economía Solidaria

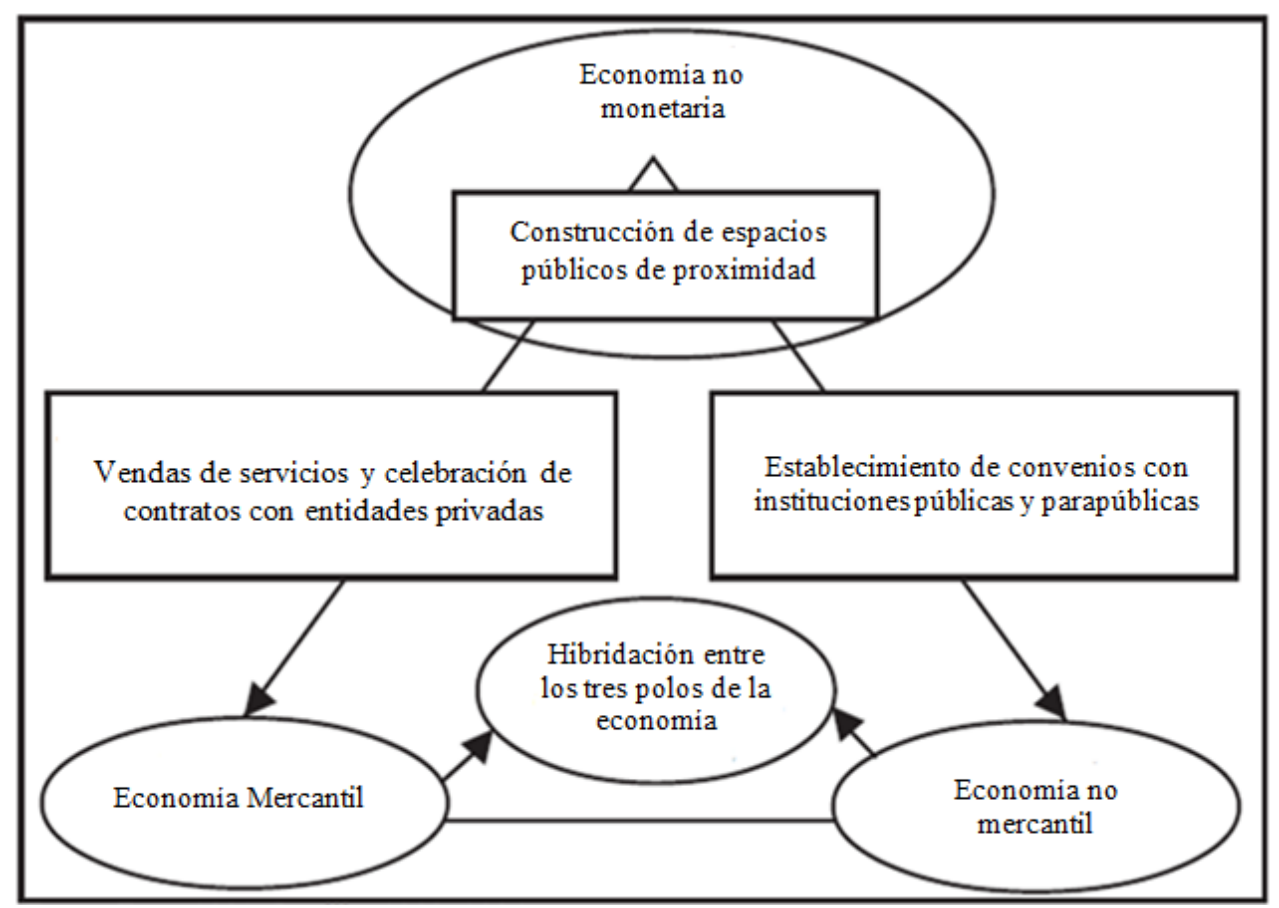

Fuente: Laville (2001)

En sus trabajos Laville deja clara la diferenciación entre la Economía Social y la Economía Solidaria, mientras que la primera asume una solidaridad de carácter filantrópico, la segunda asume una solidaridad de carácter democrático. El también reconoce la Economía Solidaria como un modo de vida y una manera diferente de hacer política.

\subsection{Organización y reconocimiento legal}

En Europa, el reconocimiento de la Economía Solidaria acontece como parte integrante de la Economía Social, que tuvo su primer reconocimiento en Francia en los años 1970, cuando organizaciones representativas de cooperativas, asociaciones y mutuas crearon el Comité National de Liaison des Activités Coopératives, mutuelles et associatves y en 1980 publicaran la Charte de léconomie sociale.

En 1989 la Economía Solidaria, como parte de la Economía Social empieza a tener reconocimiento dentro de a la Unión Europea, con la creación de un servicio específico y una comunicación sobre la Economía Social. En el año 2000 se creó la plataforma llamada Conferencia Europea Permanente de Cooperativas, Mutualidades, Asociaciones y Fundaciones (CEP-CMAF), que más tarde, en 2008 pasó a denominarse Social Economy Europe, y tiene como objetivo promover el desarrollo y el reconocimiento de la Economía Social (Fajardo, 2009).

De manera individual, el primer país europeo a reconocer legalmente la Economía Solidária fue Francia, en 1981, con la creación de una delegación de Economía Social en la presidencia del Gobierno Francés, por medio del Decreto 1125/81, con el objetivo de favorecer el desarrollo Cooperativas, sociedades mutuas y asociaciones gestoras; y por medio de la creación del Instituto de Desarrollo de la Economía Social (IDES). Sin embargo, una ley marco de la Economía Social y Solidaria en Francia sólo fue posible en 2014, cuando se promulgó la Ley 856/2014, relativa a la Economía Social y Solidaria.

La Tabla 2 presenta los países en que se identificó el reconocimiento de la Economía Social y/o Solidaria en su legislación. Se percibe la predominancia del uso de la expresión Economía Social ${ }^{4}$, distinguiendo sólo en Francia y Grecia que usam el término Economía Social y Solidaria

4 No se considera en este caso la Economía Social como sinónimo de la Economía Solidaria, pero se entiende que hay el reconocimiento de la Economía Solidaria como parte integrante de la Economía Social 
Tabla. 2. Reconocimiento de la Economía Social y Solidaria en Europa

\begin{tabular}{|l|l|}
\hline Pais & Ley \\
\hline Bélgica & $\begin{array}{l}\text { Decretos regionales: Valonia (2008); Bruselas (2012); Flandes (2012) Economía social y } \\
\text { emprendimientos sociales }\end{array}$ \\
\hline Eslovenia & Ley del Emprendedorismo Social (2011) \\
\hline España & Ley 05/2011, Economía Social \\
\hline Finlandia & Ley 1351/2003, empresas sociales \\
\hline Francia & Ley 856/2014, Economía Social e Solidaria \\
\hline Grecia & $\begin{array}{l}\text { Ley 4019/2011, Economía social y emprendimientos sociales y Ley 4430/2016, Economía Social y } \\
\text { Solidária }\end{array}$ \\
\hline Italia & Ley 118/2005, empresas sociales \\
\hline Lituania & Ley IX-2251/2004, empresas sociales \\
\hline Lujemburgo & Ley de 12 de diciembre de 2016, creación de empresas de impacto social \\
\hline Portugal & Ley 30/2013, Ley de bases de la Economía Social (LBES) \\
\hline Rumania & Ley 219/2015, Economía Social \\
\hline
\end{tabular}

Fuente: Elaboración propia.

Para Pérez de Mendiguren y Etxezarreta (2015, p. 128) no hay criterios claros que delimiten el campo organizativo de la Economía Solidaria y que en la práctica la Economía Solidaria acaba "utilizando el criterio jurídico-formal típico de la Economía Social, complementado por la apelación a los valores y principios clásicos del Cooperativismo y la Economía Social”.

La Economía Social y la Economía Solidaria son experiencias que se apoyan en el desarrollo de actividades económicas con fines sociales y lo que demarca la diferencia en la concepción de la Economía Solidaria, es la afirmación de la dimensión política en su acción (França Filho, 2002). Adicionalmente, en Europa se pone más acento en las formas de organización mientras en Latinoamérica se pone acento en lo sustantivo, las prácticas de los sujetos (Guerra, 2010).

Las principales formas jurídicas comprendidas por la Economía Social y Solidaria en Europa son: cooperativas (sociales, de trabajo, finanzas éticas, etc.), mutuales, asociaciones, fundaciones, empresas de inserción, empresas sociales, entre otras. Se destaca que la legislación y la regulación de las empresas de Economía Social y Solidaria son distintas de Latinoamérica Latina y que son definidas individualmente por cada país. Socias y Horrach (2013, p. 35) definen así las empresas de Economía Solidaria:

"Son entidades que, independientemente de su forma jurídica, ofrecen al mercado bienes o servicios a precios habituales, con lo que su fuente de ingresos prioritaria proviene de la actividad de mercado que desarrollan, y contemplan en su misión la injusticia social a través de su incorporación en el proceso productivo de inputs solidarios y el desarrollo de outputs solidarios".

Es decir, así como en Latinoamérica, lo que caracteriza a las entidades comprendidas en Economía Social y Solidaria en Europa no es su forma jurídica, sino el desarrollo de sus actividades organizacionales en pro de la transformación social.

\section{Las Plataformas de la Economía Solidaria}

Actualmente, existen diversas plataformas, a nivel local, regional, nacional y/o mundial, que actúan en colaboración unas con las otras, con el objetivo de soporte, desarrollo y la promoción de la Economía Solidaria. A nivel mundial se puede destacar la Red Intercontinental de Economía Social y Solidaria RIPESS, creada en 1997, que vincula las redes de Economía Social y de Economía Solidaria de todas las regiones del planeta y organiza foros mundiales cada cuatro años con el fin de crear un nexo para el 
aprendizaje, el intercambio de información y la colaboración. RIPESS está formada por cinco redes continentales: Réseau Africain d'économie sociale et solidaire (RAESS); Intercontinental Network for the Promotion of Social and Solidarity Economy - North America (RIPESS-NA); Asian Solidarity Economy Council (ASEC); Intercontinental Network for the Promotion of Social and Solidarity Economy - Europe (RIPESS-EU); y, Red Intercontinental de Promoción de la Economía Social y Solidaria - Latinoamérica y Caribe (RIPESS-LAC) (RIPESS, 2017).

RAESS (África) nació en el año 2010 por iniciativa de 25 organizaciones de la sociedad civil del continente y comprende al menos 14 redes nacionales: Benin, Burkina Faso, Camerún, República Democrática del Congo, Costa de Marfil, Gabón, Mauricio, Malí, Níger, Senegal, Togo, Túnez, Argelia y Marruecos.

RIPESS-NA (América del Norte) está compuesta por tres redes de Canadá (Chantier de l'économie sociale du Québec; Groupe d'économie solidaire du Québec - GESQ; y, Canadian Community Economic Development Network - CCEDNet) y una red de los Estados Unidos de América (US Solidarity Economy Network - SEN).

ASEC (Asia) está formada por 10 redes nacionales: Alliance of Philippine Partners in Enterprise Development (APPEND); Association of Social Entrepreneurs in Indonesia (AKSI); Bina Swadaya Foundation; Centre for Social Entrepreneurship, Binary University; Credit Union Promotion Centre; Hongkong Chamber of Social Enterprises; Sam Ratulangi Universiti; Universiti Kelantan Malaysia; Yayasan Kajian Dan Pembangunan Masyarakat (YKPM); y, Yayasan Sejahtera. Comprende también 8 Redes regionales y continentales: China and Beyond Network (CABN); The Common Wealth Network for People-Centred Development (COMMACT); Coalition of Socially Responsible Small \& Medium Enterprises in Asia; Ethnos Asia; Family Capital Centre; Global Citizens for Sustainable Development; Pacific Asia Resource Centre; y, World Fair Trade Organization-Asia.

RIPESS-EU (Europa) está formada por 28 organizaciones de 10 países de Europa: Alemania, Bélgica, España, Francia, Hungría, Italia, Luxemburgo, Portugal, Rumania, Suiza; y también 6 miembros transversales.

RIPESS-LAC (Latinoamérica y Caribe) incluye tres plataformas continentales: Mesa de Coordinación Latinoamericana de Comercio Justo; Coordinadora Latinoamericana y del Caribe de Pequeños Productores de Comercio Justo (CLAC); Plataforma de Economía Solidaria de Centro América (PECOSOL) Guatemala, Honduras, El Salvador, Nicaragua y Costa Rica; y, y 12 organizaciones a niveles nacionales: Argentina, Bolivia, Brasil, Chile, Colombia, Cuba, Ecuador, México, Panamá, Perú, Uruguay y Venezuela.

En Latinoamérica, en 2004, se creó el Programa Mercosur Social y Solidario, "con la impronta de sumar y hacer visible a la sociedad y en particular a los movimientos sociales, como componente estratégico de la integración de los Estados, a partir de la creación del Mercosur" (Mercosur Solidario, 2013).

Hay todavía la plataforma Socioeco.org, sitio web de recursos comunes de la Economía Social y Solidaria, que agrupa recursos documentales sobre Economía Social y Solidaria: 5.364 documentos, 1.513 publicaciones y 1.033 videos relacionados a 4.512 autores y 783 organizaciones. Recopila también 243 formaciones y 666 sitios (Socioeco.org, 2017).

Estas y otras plataformas no mencionadas tienen un papel relevante para la conexión entre los innumerables actores de la Economía Solidaria en el mundo y, especialmente, para el fortalecimiento de la Economía Solidaria como alternativa viable al sistema económico vigente.

\section{Consideraciones finales}

Teniendo en cuenta lo que se ha presentado, se deduce una evolución de la Economía Solidaria tanto en Latinoamérica y como en Europa. Sin embargo, que pendiente un debate profundo sobre la delimitación conceptual y organizativa de la Economía Solidaria. Los conceptos utilizados derivan de la realidad económica, social y cultural de cada territorio, asumiendo un carácter más político en Latinoamérica.

A partir de la comparación de las dos aproximaciones se percibe que en Europa la temática es abordada como Economía Social y Solidaria y aporta tanto organizaciones económicas de solidaridad democrática como entidades filantrópicas como las ONG y fundaciones y en relación al reconocimiento legal de la Economía Solidaria, ese reconocimiento sucede como parte de la Economía Social. En cuanto a Latinoamérica, la terminología más común es Economía Solidaria y no incluye organizaciones de carácter filantrópico como las ONG y fundaciones, centrándose en la solidaridad democrática y recibe un reconocimiento legal propio. Además, es percibida como un medio de resolver las situaciones de pobreza y las desigualdades sociales, más acentuadas en Latinoamérica. Aún así, en ambos continentes la Economía Solidaria se presenta como una economía alternativa al sistema capitalista vigente, que muestra que es posible aportar la solidaridad a las relaciones económicas.

Las diferencias están presentes en los textos analizados y forman un importante debate. Sin embargo, independientemente de los términos y conceptos, lo más relevante se centra en la discusión de los objetivos y 
acciones de estas alternativas económicas, en lo que las diversas propuestas y prácticas tienen en común y en lo que cada una aporta a la lucha por una economía más popular, solidaria, plural, inclusiva y democrática.

Además de los puntos en común que la Economía Solidaria tiene con otros movimientos como la Economía Social, la Economía Popular, dentro de otros, se trata de un término distinto, con identidad propia que ha promovido transformaciones sociales y económicas en todo el mundo por medio de experiencias que enfrentan el modelo económico actual y demuestra que no sólo es posible, sino que es necesario, un modelo alternativo de desarrollo económico y social, que sea basado en los valores de trabajo, de igualdad de derechos, de dignidad humana, de respeto a la naturaleza y la diversidad, de autogestión, de democracia, de justicia social y de libertad.

Aunque varios países ya han reconocido legalmente la Economía Solidaria, sea de forma objetiva, o incluso indirectamente a través del reconocimiento de la Economía Social, y además se observa que las experiencias solidarias están aumentando y se está produciendo un fortalecimiento de las plataformas, todavía queda mucho por avanzar y existen importantes desafíos. Asimismo, es importante que además del reconocimiento legal haya políticas públicas de fomento a las prácticas de Economía Solidaria.

\section{Referencias bibliográficas}

Colombia (1998) Ley 454/1998 - Por la cual se determina el marco conceptual que regula la economía solidaria [...]. Diario Oficial Año CXXXIV. n. 43357. 6, agosto, 1998. Acceso virtual el 26 de mayo de 2017. Disponible en: http://base.socioeco.org/docs/colombiamarcocomplementarioley454de1998.pdf.

Colombia (2018) Supersolidaria: Superintendencia de la Economía Solidaria. Reseña Historica. Acceso virtual el 27 de marzo de 2018. Disponible en: http://www.supersolidaria.gov.co/es/nuestra-entidad/resena-historica.

Coraggio, J. L. (2002) La Economía Social como vía para otro desarrollo social. Documento de lanzamiento del debate sobre "Distintas propuestas de Economía Social" en Urbared, Red de Políticas Sociales. Acceso virtual el 20 de mayo de 2017.2 Disponible en: http://www.coraggioeconomia.org/jlc/archivos\%20para\%20descargar/La\%20Economia\%20Social\%20como\%20alt ernativa\%20estructural\%204.pdf.

Coraggio, J. L. (2004) Una alternativa socioeconómica necesaria: La Economía Social. En Política Social y Economía Social: debates fundamentales. Claudia Danani (comp.). Buenos Aires: Editora Altamira, $234 \mathrm{p}$.

Coraggio, J. L. (2011) Economía Social y Solidaria: El trabajo antes que el capital. Acosta, A., y Martínez, E. eds. Quito: Abya-Yala. 412 p.

Coraggio, J. L. (2015) Desafíos en la formación profesional vinculados a la Economía Social, las políticas públicas y el Desarrollo Local. El rol de la Universidad, En Revista $+E, \mathrm{~N}^{\circ} 5$, Ediciones UNL.

Da Ros, G. S. (2007) Economía solidaria: aspectos teóricos y experiencias, UniRcoop, Vol. 5, № 1, pp. 9-27.

Farjado García, G. (2009) La Economía Social en las leyes, CIRIEC-España, Revista de Economía Pública, Social y Cooperativa, $\mathrm{N}^{\circ} 66$, pp. 5-35.

França Filho, G. C. (2002) Terceiro Setor, Economia Social, Economia Solidária e Economia Popular: traçando fronteias conceituais, Bahia: Análise \& Dados, Vol. 12, № 1, pp. 9-19.

França Filho, G. C. y Laville, J. L. (2004) Economia Solidária: uma abordagem internacional. Porto Alegre: Editora da UFRGS.

Francia. (1981) Décret n̊81-1125 du 15 décembre 1981 - Creation d'une delegation a l'economie sociale aupres du premier ministre qui est mise a la disposition du ministre du plan et de l'amenagement du territoire, et qui est dirigee par un delegue nomme par decret en conseil des ministres. JORF du 20 décembre 1981, page 3472. Acceso virtual el 26 de mayo de 2017. Disponible en: https://www.legifrance.gouv.fr/jo_pdf.do?id=JORFTEXT000000308626.

Francia. (2014) Loi $n^{\circ} 2014-856$ du 31 juillet 2014 relative à l'économie sociale et solidaire. JORF n ${ }^{\circ} 0176$ du 1 août 2014, page 12666, texte $\mathrm{n}^{\circ}$ 2. Acceso virtual el 26 de mayo de 2017. Disponible en: https://www.legifrance.gouv.fr/affichTexte.do?cidTexte=JORFTEXT000029313296\&categorieLien=id.

Gaiger, L. I. (2013) A economia solidária e a revitalização do paradigma cooperativo, Revista Brasileira de Ciências Sociais, Vol. 28, No 82, pp. 211-228. doi:10.1590/S0102-69092013000200013.

Gaiger, L. I. G. (2009) Antecedentes e expressões atuais da economia solidária, Revista Crítica de Ciências Sociais, $\mathrm{N}^{\circ}$ 84, pp. 81-99.

Guerra, P. (2004) Economía de la Solidaridad: Consolidación de un concepto a veinte años de sus primeras elaboraciones, Oikos: Revista de la Escuela de Administración y Economía, № 17, 11 p.

Guerra, P. (2006) La Economía de la Solidaridad: o la vuelta de los valores sociales a la economía, Revista Umbrales, $\mathrm{N}^{\mathrm{o}}$ 168. Acceso virtual el 23 de mayo de 2017. Disponible en: https://base.socioeco.org/docs/la-economia-de-lasolidaridad-pablo-guerra-uruguay.pdf.

Guerra, P. (2010) La economía solidaria en Latinoamérica, Papeles de relaciones ecosociales y cambio global, $\mathrm{N}^{\circ} 110$, pp. 67-76.

Guerra, P. (org) (2007) ¿Cómo denominar a las experiencias económicas solidarias basadas en el trabajo? Diálogo entre académicos latinoamericanos acerca de la polémica conceptual, Otra Economía, $\mathrm{N}^{\circ}$ 1, pp. 21-27.

Honduras. (1985) Decreto 193/1985 - Ley del Sector Social de la Economía. 14 nov. 1985. Acceso virtual el 26 de mayo de 2017. Disponible en: http://www.fao.org/faolex/results/details/en/?details=LEX-FAOC138138. 
Laville, J. L. (2001) Economia Solidária, a perspectiva europeia, Sociedade \& Estado, Vol. 16, No 1/2, pp. 57-99.

Laville, J. L. (2004) El marco conceptual de la economía solidaria, in Laville, Jean-Louis (ed.), Economía social y solidaria: Una visión europea, Altamira, Buenos Aires, pp. 207-235.

Laville, J. L. (2009) A economia solidária: Um movimento internacional, Revista Crítica de Ciências Sociais, N 84, pp. 7-47.

Laville, J. L. (2010) Economie Sociale Et Solidaire Capitalisme Et Changement Democratique. RIUESS 2010 - Xèmes Rencontres internationales du Réseau Inter-Universitaire de l'Économie Sociale et Solidaire - Luxembourg - 2 au 4 juin 2010. 16 p. Acceso virtual el 06 de junio de 2017. Disponible en: http://base.socioeco.org/docs/_index102.pdf.

Mercosur Solidario (2013) ¿Quiénes somos?. Acceso virtual el 26 de mayo de 2020. Disponible en: http://www.mercosursocialsolidario.org/quienes-somos-2/.

Monzón, J. L. y Chaves, R. (2008) The European Social Economy: concept and dimensions of the third sector, Annals of Public and Cooperative Economics, Vol. 79, No 3/4, pp. 549-577.

Monzón, J.L. y Chaves, R. (2012) La economía social en la Unión Europea. Comité Económico y Social Europeo, Bruselas. 124 p.

Pérez De Mendiguren, J. C. y Etxezarreta, E. (2015) Sobre el concepto de economía social y solidaria: aproximaciones desde Europa y América Latina, Revista de Economía Mundial, № 40, pp. 123-144.

Razeto, L. (1999) La economía de solidaridad: concepto, realidad y proyecto, Persona y Sociedad, Vol. 13, № 2, 15 p.

Razeto, L. (2002) Cinco constataciones sobre la pobreza, catorce tesis sobre el desarrollo social, y una conclusión sobre la economía solidaria, Polis - Revista Latinoamericana, $\mathrm{N}^{\mathrm{o}} 2,16 \mathrm{p}$.

Razeto, L. (2010) ¿Qué es la economía solidaria?, Papeles de Relaciones Ecosociales y Cambio Global, № 110, pp. 47 52.

Red Intercontinental de Promoción de la Economía Social y Solidaria - RIPESS. (2017) ¿Quiénes somos? Miembros y Aliados. Acceso virtual el 06 de junio de 2017. Disponible en: http://www.ripess.org/quienes-somos/nuestrosaliados/?lang=es.

Singer, P. (2001) Economia solidária versus economia capitalista, Sociedade e Estado, Vol. 16, No 1, pp. $100-112$. DOI:10.1590/S0102-69922001000100005.

Singer, P. (2002) Introdução à economia solidária. 1 ed. São Paulo: Fundação Perseu Abramo.

Singer, P. (2005) A recente ressurreição da economia solidária no Brasil. En: Santos, Boaventura Souza (Org.). Produzir para viver: Os caminhos da produção não capitalista. Reinventar a emancipação social: para novos manifestos; 2 ed. Rio de Janeiro: Civilização Brasileira, pp. 81-129.

Singer, P. (2008) Economia solidária, Estudos Avançados, Vol. 22, № 62, pp. 289-314.

Socias, A. y Horrach, P. (2013) Enfoque de la responsabilidad social y la transparencia en empresas de economía solidaria, CIRIEC-España, Revista de Economía Pública, Social y Cooperativa, No 77, pp. 31-57.

Socioeco.org (2017) Socioeco.org: website de recursos comum da economia social e solidária - Apresentación. Acceso virtual el 26 de mayo de 2017. Disponible en: http://www.socioeco.org/index_pt.html. 